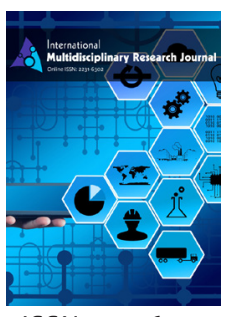

ISSN: 2231-6302

\title{
Assessment of physical and mental well-being among students of Bangladesh during COVID-19 Pandemic
}

\author{
Aurpita Shaha*, Mintu Sarker, Md. Nazmul Islam, Trishna Khatun, \\ Md. Abdul Bashir, Md. Shamim Hossain \\ Department of Pharmacy, Pabna University of Science and Technology, Pabna-6600, Bangladesh
}

\begin{abstract}
The outburst of COVID-19 influenced the lives of all segment of society as people were requested to self-quarantine in their homes to stop the outspread of the virus. The lockdown had consequential impacts on mental health, triggering psychological problems encompassing frustration, stress, and depression. The outbreak of Covid-19 has significantly affected the lives of all parts of the society. One of the most instant changes launched was the closure of educational institutions to decelerate the spreading of the virus. Students no longer had availability of institution-based physical activities such as physical education, recess, and walking to/from universities/colleges/school. Inadequate physical activities and enormous sedentary behavior amid students exhibits a noteworthy problem because health behavior patterns can result in heightened risk for a number of hazardous health conditions (e.g., overweight/obesity, type II diabetes, and metabolic syndrome) in later. The objective of this study was to explore the pervasiveness of physical and mental health condition among Bangladeshi students during the COVID-19 pandemic. It also focuses on recognizing the stimulus of various states of physical and mental conditions throughout COVID-19 pandemic. The cross sectional data was gathered by means of interviews or self-responses among the university students from various districts of Bangladesh on July to August 2020. The study was performed with structured questionnaire. To reduce threats of Covid-19 infection, in this investigation, participants were interviewed over telephone instead of face to face interaction. In order to explore the effects of this pandemic on the lives of students, we performed a survey in which a total of 576 participants were participated. In this survey, among them 377 (66\%) are male and 197 (34\%) female. It was discovered that $92 \%$ of participants appreciate participating in physical activities \& rest of them $(8 \%)$ don't like to participate in physical activities. In addition, our study also revealed $46 \%$ of the students having trouble in sleep and $45 \%$ students feels concentration problem. The findings of this study show that greater numbers of the students are not in sound physical or mental conditions. They are bored, helpless, anxious and depressed than previous. This study shows that the mental conditions of female students are more affected by Covid-19 compared to male students. $82 \%$ of female students are stressed about their study, future life and so on. $46 \%$ female students are feeling helpless, $61 \%$ become upset and $60 \%$ feel bored during lockdown and close of education institution. COVID-19 is striking threat both on physical and mental health since its outbreak. During this challenging time, it is necessary to continue taking care of physical and mental health.
\end{abstract}

* Corresponding author:

Aurpita Shaha

Email:aurpita89@yahoo.com

Keywords: COVID-19, Outbreak, Self-quarantine, Mental health, Physical health

\section{INTRODUCTION}

COVID-19 pandemic appeared as the most disastrous and strenuous crisis for public health in the present world. Apart from the escalating death rate, nations around the globe have also been going through a peak of the agonizing psychological consequences, i.e., anxiety and depression among people of all ages. Students are no exception, as all the educational institutions are astonishingly closed for more than usual, and for Bangladesh, it is more than one year in a row. Such closure, in general, generates a sense of doubt about academic and professional career among the educands and raises endless mental health challenges among students (Islam et al., 2020).

Bangladesh has different diseases burdens which are the major cause of death and disability. (Shaha et al., 2020) The global community is anxious about Coronavirus disease 2019 (COVID-19) and its long-term outcomes. It is going to affect

Copyright: ( ) Shaha, et al. This article is open access and licensed under the terms of the Creative Commons Attribution License (http://creativecommons.org/licenses/by/4.0/) which permits unrestricted, use, distribution and reproduction in any medium, or format for any purpose, even commercially provided the work is properly cited. Attribution - You must give appropriate credit, provide a link to the license, and indicate if changes were made. 
various spheres of life including the human health, health care, economy, industries, agriculture, global market etc. There were concomitant detrimental impacts of Covid-19 or lockdown in the health sector. Living under coronavirus disease (COVID-19) constraints accentuates the necessity of being physically fit and healthy. It reflects that current initiatives such as self-isolation and quarantine have influenced usual activities, routines, and livelihoods of people that may lead to an escalation in loneliness, anxiety, depression, insomnia, harmful alcohol, and drug use, and self-harm or suicidal behavior (WHO, 2020) Therefore, in addition to precautionary measures, such as periodic hand washing, social distancing, and self-isolation, individuals require to safeguard their overall physical health through physical activities. The documentation showed that people with underlying medical states, such as cardiovascular disease, diabetes, chronic respiratory disease, and cancer, face a higher risk of critical complaints from COVID-19 (WHO 2020; Huang et al., 2020; Wang et al., 2020; Yang et al., 2020; Liang et al., 2020). The community lockdowns and quarantines being applied to contain the transmission of COVID-19 are favoring physical idleness and tremendous reliance on processed and canned food, which may exacerbate the risk of metabolic diseases in the population (Jiménez-Pavón et al., 2020; Narici et al., 2020). A recent study revealed a considerable decline in physical activity \& elevation in internet screen time during the COVID-19 pandemic among children (Xiang et al., 2020). Researches have shown that inadequate physical activity and long-term sedentary behavior are associated to poor physical and mental health outcomes (Korczak et al., 2017; Haapala et al., 2017). Contrarily, the positive effects of regular physical activity on many health consequences are well renowned (Pedersen \&Saltin, 2006; Powell et al., 2011).

As the COVID-19 pandemic has been transmitting expeditiously within the world, high levels of anxiety, stress and depression have previously been noticed in the general population. Throughout pandemics, as the world experiences a shutdown or slowdown in daily activities and individuals are inspired to practice social distancing so as to minimize interactions between people, thus reducing the chances of new infections (Wilder et al., 2020). These factors can cause distinct levels of psychological pressure, which may develop perception of loneliness and helplessness, or a sequence of dysphoric emotional states, such as stress, irritability, physical and mental fatigue, and despair. These kinds of epidemics guide the public to encounter mental complications such as post-traumatic stress disorder, psychological distress, depression and anxiety (Shultz et al., 2015, Qu et al., 2014).

Wellness activities, involving good nutrition, adequate sleep, meditation, and regular exercise, have a major role in restricting COVID-19 infection as well as in coming back from COVID-19. The immune system shields against viruses and diseases and generate antibodies to kill pathogens. Antibiotics exerts the effect on immune systems and the underlying mechanism of immunomodulation are unknown (Shaha et al., 2016a,b, Islam et al., 2016). Herbal medicine, which has an immunemodulatory effect, has a crucial role in allergic rhinitis, lung infection, (Shaha et al., 2018, Islam et al., 2018) could have promising as an inhibitory measure and even therapeutic agent for patients with COVID-19 infection. COVID-19 outlasters need healthy nutrition, good care, and engagement in wellness activities to fully heal and acquire their lives continuing as expected.

\section{METHODS AND MATERIALS}

\section{Study Design}

The study was semi structured, cross-sectional and descriptive in nature. This study was pre-planned to bring about the actual scenario of physical activity and mental status amid university students during COVID-19 situation. The contributors of this investigation were the students of different public and private universities of Bangladesh from different regions.

\section{Sample Design}

For the survey part of the study, age stratified sampling technique was used for selecting the study sample. Both male \& female sample with an age range of 18-27 years were interviewed. Samples were from Home in COVID situation. The number of sample different university selected randomly for an average scenario. A total of 576 samples were interviewed by Google based online form individually \& via phone calls for desired response from the respondents.

\section{Data Collection and Study Procedures}

The questionnaire survey was directed from 16 July to 26 July, 2020 during the COVD-19 pandemic. As a community-based national sampling survey during this time was not feasible, data was gathered online along with phone calls to serve the aim of the research. Google Form based online questionnaire was prepared to conduct the survey. A total of 23 items was investigated in the drafted questionnaires to get people's perception of the COVID-19 outbreak in Bangladesh.

The drafted questionnaire with an introductory paragraph outlining the purpose of the study was shared through Facebook $\&$ Email with selective and relevant people considering the purposive sampling method. The initial survey was written in English and then translated into Bangla by a researcher fluent in both languages. The survey was piloted with a small online user group to test its clarity. We communicated with the respondents via phone calls in accordance with prepared Google questionnaire and data from 576 respondents were collected. The answers to the survey questionnaires are on a voluntary basis.

\section{Ethical Consideration}

All the data collected was used only for research purpose and respondents were assured that, any unauthorized use of the data that can affect the confidentially will be strongly prohibited. All the participants participated willingly. 


\section{Statistical Analysis}

To analyze the data, a set of statistical tools have been applied. Descriptive statistics consisting of frequencies and percentages of categorical data have been used to obtain the characteristics of the participants using Microsoft Excel 2010 software.

\section{RESULTS}

The participants were aged from 18 to 27 above years \& most of them were undergraduate studnts from various renowned universities across the country. Among the respondents $28 \%$ of belong to the age range 18 20,37\% belong to the age range $21 \sim 23,32 \%$ belong to the age range $24 \sim 26 \& 2 \%$ of the respondents belong to the age range $27 \&$ above as shown in the Figure 1. Most of the participants that were involved in this study were male. Table 1 represents that among the participants $66 \%$ were male\& $34 \%$ were female.

It is important during isolation/lockdown that we find ways to maintain our activity levels as many of us aren't getting in as much movement as we typically would. While it may seem easier to curl up on the couch when we're confined at home, we should try to think of this time as an opportunity to set our physical activity goals and think of ways to build long term sustainable habits into our daily schedule. Now is the perfect time to find ways to integrate physical activity into our lifestyle. In this study among the participants only $92 \%$ (Table 2 ) of them enjoys participating in physical activities \& rest of them $(8 \%)$ don't like to participate in physical activities.

This study shows $73 \%$ respondents perform household activities. (Table 3 ) represents that respondents who performs household activities, among them $30 \%$ respondents helps their parents in various way, $20 \%$ of them does cooking, $27 \%$ does cleaning \&washing room, $8 \%$ of does agricultural work \& remaining $15 \%$ respondents does things like going to market.

Participants spending several months in lockdown and it's no surprise that the motivation to do exercise on a regular term and maintaining fitness has been a bit of struggle. Besides the closure of parks, gyms, fitness classes and restriction to outdoor group sporting activities is also not helping.

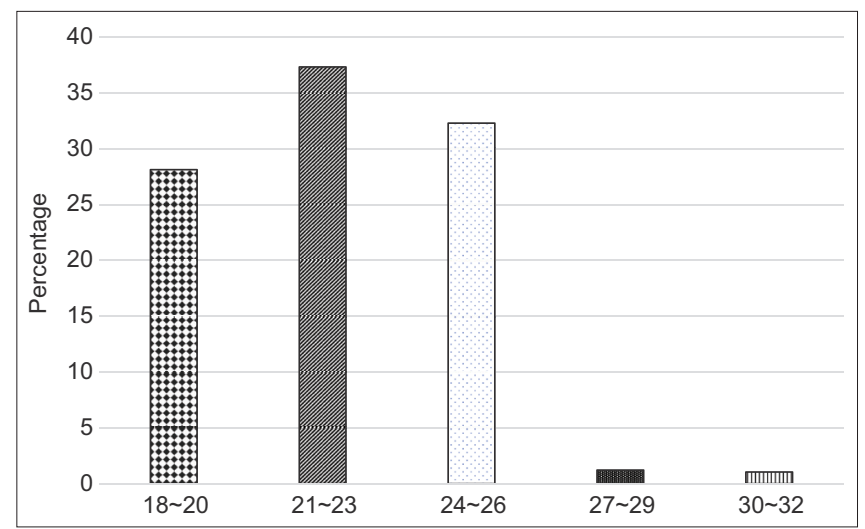

Figure 1: Respondents of age varieties
As the Table 1.3 shows that $72 \%$ of respondents do walking, $7 \%$ of respondents do running, $4 \%$ of them do yoga and rest of the respondents (17\%) does other forms of exercises including gym.

COVID-19 pandemic came out as the most devastating and challenging crisis for public health in the contemporary world. Apart from the soaring mortality rate, nations across the globe have also been suffering from a spike of the excruciating

Table 1: Characteristics of participants

\begin{tabular}{lc}
\hline Variables & Value \\
\hline Total No. of participants & 576 \\
Male students & $377(66 \%)$ \\
Female students & $197(34 \%)$ \\
Level of study & Universities student \\
Faculty of students & $375(65 \%)$ Science faculty \\
Average age & $21.75+2.36$ \\
\hline
\end{tabular}

Table 2: Frequency table for different selected variables

\begin{tabular}{lcc}
\hline Variables & Frequency & Percentage \\
\hline Sleep disturbance & & \\
Yes & 264 & 44 \\
No & 323 & 56 \\
Satisfaction with academic study under present circumstances & \\
$\quad$ Yes & 512 & 89 \\
No & 63 & 11 \\
Physical activities & & \\
Yes & 530 & 92 \\
No & 46 & 8 \\
Smoking/Alcohol/Drug & & \\
Yes & 80 & 14 \\
No & 496 & 86 \\
Anxiety & & \\
$\quad$ Yes & 248 & 43 \\
No & 328 & 57 \\
Concentration disturbance & & \\
Yes & 261 & 45 \\
No & 315 & 55 \\
Depression & & \\
Yes & 253 & 44 \\
No & 323 & 56 \\
Stressed & & \\
Yes & & 77 \\
No \\
Worried about future/session Jam & 134 & 23 \\
Yes & & \\
No & 506 & 12 \\
\hline
\end{tabular}

Table 3: Respondents participates on different Physical activities

\begin{tabular}{lcc}
\hline & $\mathrm{n}$ & Percentage \\
\hline Household activities & & \\
Cooking & 84 & 20 \\
Helping Parents & 124 & 30 \\
Cleaning & 116 & 27 \\
Agriculture & 32 & 8 \\
Going Market & 64 & 15 \\
Physical Activities & & \\
Walking & 412 & 72 \\
Running & 38 & 7 \\
Yoga & 25 & 4 \\
Others & 57 & 10 \\
Gym & 44 & 7 \\
\hline
\end{tabular}


psychological outcomes, i.e. anxiety and depression among people of all ages. It is entirely reasonable to feel upset considering the lockdown situation that is exactly what was found among the participants. Almost half of the total number of participants responded positively while asked whether they are feeling upset quite often during the COVID-19 situation, i.e. lockdown. People with past mental disorders are particularly vulnerable to these effects. Because of the pandemic, all these problems would have much greater impacts on children and teenagers. (Table 2) shows that $44 \%$ of Participants feel depression, $46 \%$ of Participants feel insomnia, $43 \%$ participants feel anxiety and $45 \%$ students feel concentration disturbance. Lockdown can be a very stressful period for many of us. Our life changed a lot during the last few weeks, and this lockdown situation can increase stress and anxiety. You might feel fear of getting sick or face uncertainty on how COVID-19 will affect you socially and economically

In such a critical situation, it is normal to feel sad, worried, scared or angry - or even all these emotions at once. Table 2 represents that $78 \%$ of the respondents feeling stressed. Among them $34 \%$ of them feeling extremely stressed \& the remaining $57 \%$ of the respondents feel moderate stress while remaining are not feeling any stress during the lockdown due to COVID-19.

Table 1.2 shows that $88 \%$ of the respondents feeling anxious of the current situation, while thinking about session jam/ unemployment \& other relevant things. Similarly, living alone, having a lower educational background, and being technically unemployed increased the odds of smoking more cigarettes during the lockdown as well. As the Table 2 represents that $14 \%$ of the participants have taken things like drug, alcohol, nicotine etc. to overcome or feel better.

This study reveals that the mental condition of female students are more affected by Covid-19 compared to male students. $82 \%$ of female students are stressed about their study, future life and so on. $46 \%$ female students are feeling helpless, $61 \%$ become upset and $60 \%$ feel bored during lockdown and close of education institution. (Table 4)

\section{DISCUSSION}

In this investigation, we evaluated the factors that affect physical \& mental health conditions among the youth round about two months after the appearance of COVID-19. This investigation gives the nationwide data on physical wellness, stress levels, anxiety symptoms, and distressing symptom etc. among students presently studying in public, private \& national universities during the COVID-19 pandemic.

Our investigation reveals that COVID-19 pandemic is related to elevated physical \& mental health issues. In our analysis we discovered most of the respondents' were materially quite well \& $6 \%$ of them were replied negatively. Amid those participants they are mainly facing depression \& other mental health problems $\&$ some of them are also experiencing sleep disturbances which influenced their standard of life during the COVID-19 pandemic. Our study reflects that this COVID-19 pandemic has significantly impacted the people on performing physical activities; $95 \%$ of participants engaged in physical activities in different ways. In France almost after 2 months of quarantine identical investigation indicates that the COVID-19 pandemic influenced the number of people participating in group physical activity programs mainly due to the fear of meeting likely infected people (WHO, 2020) In this investigation (Table-1.3) it was shown that most of the participants $(72 \%)$ evaluated limited walking as their principal form of exercise \& some of others engaged in running, yoga \& other forms of exercises. Since innumerable people are working from home schedules due to quarantine, engaged to lesser movement or exercise $\&$ there has been a conventional rise in the texting activity, video conferencing, hours of internet activity such as online courses, webinars and all other prime duties are at present done by depending on internet and technology. This reduced bodily activity \& the heightened use of handheld devices such as mobile phones, tablets, game controls, personal digital assistants and portable media players has led to a rise in the musculoskeletal problems during the quarantine period ( $\mathrm{Lu}$ et al., 2020)

In our study (Table 2) we discovered among the respondents only $14 \%$ of them are like to be involved in smoking/drugs/ alcohol. Though the number is not large enough but keeping in mind our study population and age ranges (18-27) it is quite a frightening number (Figure 1). During long periods of isolation light inconsistent smokers can be transformed into heavy or regular consumers, which is surely an issue to think about. Earlier study shows that Over $45 \%$ of smokers encountered a rise in smoking repetition during the quarantine (Xiang et al., 2014).

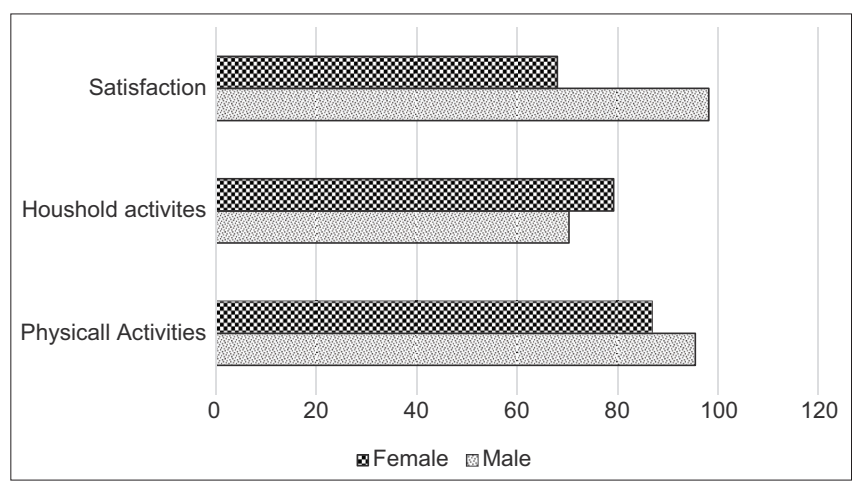

Figure 2: Comparison of physical activities among male and female students

Table 4: Comparison of stress, anxiety, boredom, and depressive symptoms among male and female students based on perceptions of COVID-19

\begin{tabular}{lcc}
\hline Mental Condition & $\begin{array}{c}\text { Male student } \\
\text { (percentage) }\end{array}$ & $\begin{array}{c}\text { Female student } \\
\text { (percentage) }\end{array}$ \\
\hline Depression & 47 & 38 \\
Boredom & 45 & 60 \\
Anxiety & 34 & 61 \\
Insomnia & 43 & 52 \\
Concentration disturbance & 44 & 49 \\
Stressed & 76 & 82 \\
Helpless feeling & 28 & 46 \\
\hline
\end{tabular}


Table 1.2 demonstrated $89 \%$ of the participants were worried about their academic education. Among them 174 participants (34\%) were intensely stressed, 58\% reasonably stressed and 8\% had a little stressed on their academic career. Unpredictability about future, Fear of losing livelihood, restricted leisure opportunities, forbidden social community events, significantly restricted social relationships to the closest family members \& peer communication etc. can be accountable to generate this kind of perception too often. Related concerns are lifted elsewhere as well (National Health commission, 2020) i.e. that the anticipated mental/physical health outcomes of coronavirus pandemic can be more or less figured and will probably include: intense fear and anxiety; lowered sense of health; uninterested societal behaviors guided by fear and distorted feeling of risk which will lead to feeling of dissatisfaction too often.

This investigation shows that the mental states of female students are more disturbed by Covid-19 in contrast to male students (Table 1.4). 82\% of female students are stressed about their study, future life and so on. $46 \%$ female students are feeling helpless, 61\% become upset and 60\% feel bored during lockdown and shut down of education institution.

It is observed to be a dark and distressing feeling, a threat for many mental problems like depression, anxiety, adjustment disorder, chronic stress, insomnia or even late-life dementia. Social isolation resulting in chronic loneliness and boredom, which if long enough can have deleterious effects on physical and mental well-being. In addition, loneliness has also proved to be a distinct risk factor for sensory loss, connective tissue and autoimmune disorders, cardio-vascular disorders and obesity. Earlier study indicates due to prolong self-isolation and lockdown it is probable that chronic loneliness will reduce physical activity resulting in elevated risk of frailty and fractures (Bao et al., 2020). Anciently quarantine has been associated with anxiety, depression, panic, irritability, somatic disorder, and insomnia. Moreover, an increased level of stress and trauma-related diseases are byproducts of being isolated. Aspects like a prolonged period of isolation, fear of infection, uncertainty, disappointment, fatigue, stigma, inadequate data and information concerning the disease, inadequate supplies, and economic devastation also negatively impact person's psychological wellbeing.

Psychosocial stressors like anxiety, stress, altered lifestyle with little to no social support, and fear may influence the framework of sleep amid individual often resulting in sleep disorders (Huang et al., 2020, Kang et al., 2020). Sleep is an essential physiological activity in keep pace with physical and mental wellbeing and better life quality. Contemporary researches have manifested that sleep disorders impact up to 1 in 4 adults (Xiang et al., 2020). They are also observed to be related to a wide range of adverse health outcomes, for example, elevated risk of obesity, diabetes, hypertension, cerebrovascular diseases, malignancy, musculoskeletal diseases, septicemia, and metabolic syndrome. A substantial amount of proof indicates a high pervasiveness of various forms of sleep disorders in the global community. This situation is likely to worsen in the current circumstances with numerous psychological stressors. In our investigation (Table 1.2) we discovered $46 \%$ of the participants having sleep disturbances like having trouble falling or staying asleep or sleeping too much. Among them female students have high sleep disturbance compared to male students.

COVID-19 pandemic has affected women differently than it has affected men: women reported more sleep troubles, more symptoms of anxiety and depression, and greater empathy for others. (Thibaut et al., 2020). This study also showed that the mental conditions of female students are more affected by Covid-19 compared to male students. The comparison showed $61 \%$ become upset whereas male students percentage is about $34 \%$ and $60 \%$ feel boredom symptoms whereas male students are $45 \%$ during lockdown and close of education institution. (Table 1.4) It is reported that Women are two to three times more predicted to be diagnosed with anxiety disorder.

\section{CONCLUSION}

This investigation indicates the actual structure of Bangladeshi students who have been suffering from depression and anxiety symptoms and other physical problems during the current pandemic situation. In addition to academic and professional uncertainty, financial insecurity is promoting to the growth of depression and anxiety among students. To reduce the growing mental health problems, the government, along with the institutions, should work jointly to provide rapidly and precisely economy-oriented physical and psychological support to the students.

\section{REFERENCES}

Bao, Y., Sun, Y., Meng, S., Shi, J., and Lu, L. (2020). 2019-nCoV epidemic: address mental health care to empower society. Lancet, 395(10224), e37-e38. https://doi.org/10.1016/S0140-6736(20)30309-3

Haapala, E. A., Väistö, J., Lintu, N., Westgate, K., Ekelund, U. Poikkeus, A. M., Brage, S., and Lakka, T. A. (2017). Physical activity and sedentary time in relation to academic achievement in children. Journal of Science and Medicine in Sport, 20(6), 583-589. https://doi.org/10.1016/j.jsams.2016.11.003

Huang, J. Z., Han, M. F., Luo, T. D., Ren, A. K., and Zhou, X. P. (2020). Mental health survey of 230 medical staff in a tertiary infectious disease hospital for COVID-19. Chinese Journal of Industrial Hygiene and Occupational Diseases, 38(3), 192-195. https://doi.org/10.3760/ cma.j.cn121094-20200219-00063

Islam, M. A., Barna, S. D., Raihan, H., Khan, M., and Hossain, M. T. (2020). Depression and anxiety among university students during the COVID-19 pandemic in Bangladesh: A web-based cross-sectional survey. PloS one, 15(8), e0238162. https://doi.org/10.1371/journal. pone.0238162

Islam, R., Mizuguchi, H., Shaha, A., Nishida, K., Yabumoto, M., Ikeda, H., Fujino, H., Kitamura, Y., Fukui, H., and Takeda, N. (2018). Effect of wild grape on the signaling of histamine $\mathrm{H} 1$ receptor gene expression responsible for the pathogenesis of allergic rhinitis. Journal of Medical Investigation, 65(3.4), 242-250. https://doi.org/10.2152/ jmi.65.242

Islam, R., Shaha, A., Sarder, M. N., and Hossain M., (2016). Isolation and identification of Bacillus species from soils and studies on their secondary metabolites. International Journal of Current Trends in Pharmacobiology and Medical Sciences, 1(3), 16-24

Jiménez-Pavón, D., Carbonell-Baeza, A., and Lavie, C. J. (2020). Physical exercise as therapy to fight against the mental and physical consequences of COVID-19 quarantine: Special focus in older people. Progress in cardiovascular diseases, 63(3), 386-388. https:// doi.org/10.1016/j.pcad.2020.03.009 
Kang, L., Li, Y., Hu, S., Chen, M., Yang, C., Yang, B. X., Wang, Y., Hu, J., Lai, J., Ma, X., Chen, J., Guan, L., Wang, G., Ma, H., and Liu, Z. (2020). The mental health of medical workers in Wuhan, China dealing with the 2019 novel coronavirus. The Lancet. Psychiatry, 7(3), e14. https:// doi.org/10.1016/S2215-0366(20)30047-X

Korczak, D. J., Madigan, S., Colasanto, M. (2017). Children's physical activity and depression: A meta-analysis. Pediatrics, 139(4), e20162266. https://doi.org/10.1542/peds.2016-2266

Liang, W. H., Guan, W. J., Li, C. C., Li, Y. M., Liang, H. R., Zhao, Y., Liu, X. Q., Sang, L., Chen, R. C., Tang, C. L., Wang, T., Wang, W., He, Q. H., Chen, Z. S., Wong, S. S., Zanin, M., Liu, J., Xu, X., Huang, J., Li, J. F., Ou, L. M., Cheng, B., Xiong, S., Xie, Z. H., Ni, Z. Y., Hu, Y., Liu, L., Shan, H., Lei, C. L., Peng, Y. X., Wei, L., Liu, Y., Hu, Y. H., Peng, P., Wang, J. M., Liu, J. Y., Chen, Z., Li, G., Zheng, Z. J., Qiu, S. Q., Luo, J., Ye, C. J., Zhu, S. Y., Cheng, L. L., Ye, F., Li, S. Y., Zheng, J. P., Zhang, N. F., Zhong, N. S., and He, J. X. (2020). Clinical characteristics and outcomes of hospitalised patients with COVID-19 treated in Hubei (epicentre) and outside Hubei (non-epicentre): a nationwide analysis of China. The European Respiratory Journal, 55(6), 2000562. https://doi.org/10.1183/13993003.00562-2020

Lu, R., Zhao, X., Li, J., Niu, P., Yang, B., Wu, H., Wang, W., Song, H., Huang, B., Zhu, N., Bi, Y., Ma, X., Zhan, F., Wang, L., Hu, T., Zhou, H., Hu, Z., Zhou, W., Zhao, L., Chen, J., Meng, Y., Wang, J., Lin, Y., Yuan, J., Xie, Z., Ma, J., Liu, W. J., Wang, D., Xu, W., Holmes, E. C., Gao, G. F., Wu, G., Chen, W., Shi, W., and Tan, W. (2020). Genomic characterisation and epidemiology of 2019 novel coronavirus: implications for virus origins and receptor binding. Lancet, 395(10224), 565-574. https://doi.org/10.1016/S0140-6736(20)30251-8

Narici, M., Vito, G., Franchi, M., Paoli, A., Moro, T., Marcolin, G., Grassi, B., Baldassarre, G., Zuccarelli, L., Biolo, G., di Girolamo, F. G., Fiotti, N., Dela, F., Greenhaff, P., and Maganaris, C. (2021). Impact of sedentarism due to the COVID-19 home confinement on neuromuscular, cardiovascular and metabolic health: Physiological and pathophysiological implications and recommendations for physical and nutritional countermeasures. European Journal of Sport Science, 21(4), 614-635. https://doi.org/10.1080/17461391. 2020.1761076

National Health Commission. (2020). Update on epidemic situation of novel coronavirus-infected pneumonia.

Pedersen, B. K., and Saltin, B. (2006). Evidence for prescribing exercise as therapy in chronic disease. Scandinavian Journal of Medicine and Science in Sports, 16(S1), 3-63. https://doi.org/10.1111/j.16000838.2006.00520.x

Powell, K. E., Paluch, A. E., and Blair, S. N. (2011). Physical activity for health: What kind? How much? How intense? On top of what?. Annual Review of Public Health, 32, 349-365.

Qu, Z., Wang, C. W., Zhang, X., Ho, A. H., Wang, X., and Chan, C. L.
(2014). Prevalence and determinants of depression among survivors 8 months after the Wenchuan earthquake. The Journal of Nervous and Mental Disease, 202(4), 275-279. https://doi.org/10.1097/ NMD.0000000000000118

Shaha A., Haque A., and Islam A. (2016b). Studies on secondary metabolites of Streptomyces species contaminated bacteria. World Journal of pharmacy and Pharmaceutical Sciences, 5(11), 218-234.

Shaha, A., Haque, A., Haque, U., and Islam A. (2016a). Identification of Bacteria that Contaminate Stored Streptomycin Species at $4^{\circ} \mathrm{C}$ International Journal of Current Microbiology and Applied Sciences, 5(9), 617-625. https://doi.org/10.20546/ijcmas.2016.509.070

Shaha, A., Mizuguchi, H., Kitamura, Y., Fujino, H., Yabumoto, M., Takeda, N., and Fukui, H. (2018). Effect of Royal Jelly and Brazilian Green Propolis on the Signaling for Histamine H1 Receptor and Interleukin-9 Gene Expressions Responsible for the Pathogenesis of the Allergic Rhinitis. Biological and Pharmaceutical Bulletin, 41(9), 1440-1447. https://doi. org/10.1248/bpb.b18-00325

Shaha, A., Rahman, M. A., Yousuf, M. P. B., Sultana, S., Islam, S. M. A., Ahmed, R., Islam, M. S., and Sultana, R. (2020). Complications of type-2 diabetes among patients of pabna district in bangladesh: a survey based study. International Journal of Current Research, 12(9), 13876-13880. https://doi.org/10.24941/ijcr.39725.09.2020

Thibaut, F., and van Wijngaarden-Cremers, P. J. M. (2020) Women's Mental Health in the Time of Covid-19 Pandemic. Frontiers in Global Women's Health, 1, 588372. https://doi.org/10.3389/fgwh.2020.588372

Wang, C., Pan, R., Wan, X., Tan, Y., Xu, L., Ho, C. S., and Ho, R. C. (2020), Immediate Psychological Responses and Associated Factors during the Initial Stage of the 2019 Coronavirus Disease (COVID-19) Epidemic among the General Population in China. International Journal of Environmental Research and Public Health, 17(5), 1729. https://doi.org/10.3390/ijerph17051729

WHO. (2020). WHO calls for urgent, aggressive actions to combat COVID-19, as cases soar in South-East Asia Region. Retrieved from https://www.who.int/southeastasia/news/detail/17-03-2020-whocalls-for-urgent-aggressive-actions-to-combat-covid-19-as-casessoar-in-south-east-asia-region

Xiang, M., Zhang, Z., and Kuwahara, K. (2020). Impact of COVID-19 pandemic on children and adolescents' lifestyle behavior larger than expected. Progress in Cardiovascular Diseases, 63(4), 531-532. https://doi.org/10.1016/j.pcad.2020.04.013

Xiang, Y. T., Yang, Y., Li, W., Zhang, L., Zhang, Q., Cheung, T., and Ng, C. H. (2020). Timely mental health care for the 2019 novel coronavirus outbreak is urgently needed. The Lancet. Psychiatry, 7(3), 228-229. https://doi.org/10.1016/S2215-0366(20)30046-8

Xiang, Y. T., Yu, X., Ungvari, G. S., Correll, C. U., and Chiu, H. F. (2014). Outcomes of SARS survivors in China: not only physical and psychiatric co-morbidities. East Asian Archives of Psychiatry, 24(1), 37-38. 